\title{
PENGARUH HUMAN CAPITAL, STRUCTURAL CAPITAL, DAN RELATIONAL CAPITAL TERHADAP AKREDITASI UNIVERSITAS WIDYATAMA
}

\author{
Neneng Susanti \\ Fakultas Ekonomi dan Bisnis Universitas Widyatama \\ neneng.susanti@widyatama.ac.id \\ R. Achmad Drajat Aji Sujai \\ Fakultas Ekonomi dan Bisnis Universitas Widyatama \\ ahmad.drajat@widyatama.ac.id \\ Eristy Minda Utami \\ Fakultas Ekonomi dan Bisnis Universitas Widyatama \\ eristy.minda@widyatama.ac.id
}

\begin{abstract}
The purpose of this research is to analyze the influence of human capital, structure capital, and relational capital on the accreditation of Widyatama University. This is an exploratory research applying associative research method. The data used is primary data. Data were analyzed using Structural Equation Modeling (SEM) with AMOS statistical software package. The results of this study show that human capital is the most dominant factor affecting accreditation, which is $15.35 \%$, even though statistically it has no significant influence. Overall, intellectual capital factor has no effect on accreditation. Relational and structural capitals have negative effects on accreditation and statistically have insignificant influence.
\end{abstract}

Keywords: Human Capital, Structure Capital, Relational Capital, Accreditation, and Widyatama University.

Abstrak: Tujuan dari penelitian ini adalah untuk menganalisis pengaruh human capital, structure capital, dan relational capital terhadap akreditasi Universitas Widyatama. Pendekatan yang digunakan adalah model exploratory research dengan metode penelitian asosiatif. Data yang digunakan dalam penelitian ini adalah data primer. Data dianalisis menggunakan SEM dari paket software statistik AMOS. Hasil penelitian menunjukkan bahwa faktor yang paling dominan berpengaruh terhadap akreditasi adalah human capital, yaitu sebesar 15,35\%, namun secara statistik tidak berpengaruh signifikan. Secara keseluruhan, faktor intellectual capital tidak berpengaruh terhadap akreditasi, bahkan relational dan structural capital memiliki pengaruh yang negatif terhadap akreditasi, meskipun secara statistik tidak signifikan.

Kata Kunci: Human Capital, Structure Capital, Relational Capital, Akreditasi, dan Universitas Widyatama

\section{Pendahuluan}

Tantangan yang dihadapi Perguruan Tinggi dewasa ini semakin menujukan intensitas yang cepat dan komplek. Hal ini akan berpengaruh pada penyelenggaraan Perguruan Tinggi. Pada masa ini, tantangan bagi Perguruan Tinggi yang perlu dicermati dan disikapi dengan tepat yaitu makin menguatnya kehidupan masyarakat berbasis pengetahuan (Knowledge based society), eskalasi perkembangan ilmu 
pengetahuan yang sangat cepat dan variatif baik kedalamannya maupun keluasannya, meningkatnya tuntutan akan penyelenggaraan pendidikan tinggi yang berbasis riset, meningkatnya tuntutan akan hasil pendidikan yang bermutu, meningkatnya tuntutan akan kiprah lulusan pendidikan (outcome) yang relevan, dan meningkatnya tuntutan proses penyelenggaraan pendidikan yang bermutu dengan standar tertentu. (uharsputra.wordpress.com).

Di dalam sebuah perguruan tinggi, kolaborasi dari segala output tersebut dapat tercermin dalam sebuah akreditasi. Akreditasi merupakan hal yang sangat penting bagi sebuah perguruan tinggi karena akreditasi merupakan bentuk nyata kualitas dan kredibilitas dari setiap universitas. Akreditasi merupakan pemikat sebuah perguruan tinggi untuk menjadi daya tarik bagi calon mahasiswa, dosen, dan juga perusahaan pemberi lapangan pekerjaan.

Universitas Widyatama (UTama) menyadari pentingnya akreditasi bagi institusi. Hal ini menjadi semakin penting dengan adanya fakta bahwa semakin hari, akreditasi semakin menjadi prioritas utama bagi para calon mahasiswa dalam memilih UTama sebagai tempat untuk menjembatani cita-citanya. Berikut adalah tabel peringkat hal - hal yang menjadi alasan calon mahasiswa memilih UTama.

tabel 1. Data Alasan Calon Mahasiswa Memilih UTama

\begin{tabular}{|c|c|c|c|c|c|c|c|c|}
\hline \multirow{2}{*}{ No } & \multicolumn{2}{|c|}{ TA 2013/2014 } & \multicolumn{2}{|c|}{ TA 2014/2015 } & \multicolumn{2}{|c|}{ TA 2015/2016 } & \multicolumn{2}{|c|}{ TA 2016/2017 } \\
\hline & Faktor & $\%$ & Faktor & $\%$ & Faktor & $\%$ & Faktor & $\%$ \\
\hline 1 & $\begin{array}{c}\text { Kelengkapan } \\
\text { Fasilitas }\end{array}$ & 0,16 & Akreditasi & 0,19 & Akreditasi & 0,2 & Akreditasi & 0,2 \\
\hline 2 & $\begin{array}{l}\text { Ketersediaan } \\
\text { Program studi }\end{array}$ & 0,16 & $\begin{array}{c}\text { Ketersediaa } \\
\text { n Program } \\
\text { Studi / } \\
\text { Jurusan }\end{array}$ & 0,17 & $\begin{array}{c}\text { Ketersediaa } \\
\text { n Program } \\
\text { Studi / } \\
\text { Jurusan } \\
\end{array}$ & 0,19 & $\begin{array}{c}\text { Ketersediaa } \\
\text { n Program } \\
\text { Studi / } \\
\text { Jurusan }\end{array}$ & 0,18 \\
\hline 3 & Akreditasi & 0,15 & $\begin{array}{c}\text { Kelengkapa } \\
\text { n Fasilitas }\end{array}$ & 0,15 & $\begin{array}{c}\text { Kelengkapa } \\
\text { n Fasilitas }\end{array}$ & 0,15 & Lokasi & 0,14 \\
\hline 4 & Biaya Kuliah & 0,13 & Lokasi & 0,13 & Lokasi & 0,12 & $\begin{array}{c}\text { Kelengkapa } \\
\text { n Fasilitas }\end{array}$ & 0,13 \\
\hline 5 & Kualitas Dosen & 0,1 & $\begin{array}{c}\text { Kualitas } \\
\text { Dosen }\end{array}$ & 0,1 & $\begin{array}{c}\text { Kualitas } \\
\text { Dosen }\end{array}$ & 0,1 & $\begin{array}{l}\text { Kualitas } \\
\text { Dosen }\end{array}$ & 0,09 \\
\hline 6 & Lokasi & 0,09 & Biaya Kuliah & 0,09 & Biaya Kuliah & 0,07 & Biaya Kuliah & 0,08 \\
\hline 7 & Prestasi & 0,09 & Prestasi & 0,08 & Prestasi & 0,06 & Profil Alumni & 0,08 \\
\hline 8 & $\begin{array}{l}\text { Ketersediaan } \\
\text { Beasiswa }\end{array}$ & 0,08 & Profil Alumni & 0,06 & Profil Alumni & 0,06 & Prestasi & 0,07 \\
\hline 9 & Profil Alumni & 0,04 & $\begin{array}{l}\text { Ketersediaa } \\
\text { n Beasiswa }\end{array}$ & 0,04 & $\begin{array}{l}\text { Ketersediaa } \\
\text { n Beasiswa }\end{array}$ & 0,04 & $\begin{array}{l}\text { Ketersediaa } \\
\text { n Beasiswa }\end{array}$ & 0,05 \\
\hline 10 & Lainnya & 0 & Lainnya & 0,01 & Lainnya & 0,01 & Lainnya & 0,04 \\
\hline & Total & 1 & Total & 1 & Total & 1 & Total & 1 \\
\hline
\end{tabular}


Berdasarkan tabel tersebut, dapat dilihat bahwa pada tahun akademik 2013/2014 akreditasi menjadi urutan ketiga yang menjadi alasan calon mahasiswa memilih UTama, pada tahun - tahun berikutnya akreditasi menjadi prioritas pertama dan memiliki presentasi yang semakin tinggi hingga mencapai $20 \%$. Hal ini membuktikan bahwa akreditasi merupakan masalah yang sangat penting bagi universitas guna menarik calon mahasiswa untuk menempuh studi pada universitas tersebut.

Pentingnya sebuah akreditasi mendorong UTama untuk meraih akreditasi terbaik agar terbentuknya kepercayaan masyarakat akan kualitas dosen, fasilitas, dan lulusan UTama. Berbagai upaya yang dilakukan UTama untuk meningkatkan akreditasi tentunya harus didukung oleh berbagai pihak. Seluruh civitas akademika termasuk pimpinan universitas harus mendukung peningkatan akreditasi melalui berbagai kebijakan yang dapat membantu peningkatan tersebut. Kebijakan tersebut tidak hanya berhubungan dengan aset berwujud tetapi juga aset tidak berwujud seperti intellectual capital.

Pengembangan organisasi berbasis informasi dan pengetahuan terletak pada praktek manajemen dan proses pengelolaan intellectual capitalnya. Pengelolaan intellectual capital harus disertai dengan struktur manajemen yang baik agar aset tidak berwujud yang diperlukan tersedia. Artinya, pengelolaan intellectual capital menjadi isu yang cukup penting saat ini. Pengelolaan intellectual capital yang efektif dan efisien dapat meningkatkan kapabilitas organisasi (Kostagiolas, 2012). Namun faktanya, sebagian besar organisasi tidak menyadari pentingnya pengelolaan intellectual capital dalam proses bisnis mereka (Gibb \& Blili, 2012).

Universitas selalu dituntut untuk mengembangkan modal intellectual guna meningkatkan mutu lulusannya. Modal intelektual terdiri dari human capital, structure capital, dan relational capital. Human capital meliputi profesional competence, social competence, dan motivasi. Kemudian structure capital mencakup budaya akademik dan sistem pengajaran. Selanjutnya relational capital mencakup relasi dengan konsumen, relasi dengan rekan kerja, dan relasi dengan publik.

UTama melaksanakan berbagai upaya pada human capital dengan memberikan dukungan kepada dosen - dosen yang akan melakukan studi lanjut, mempublikasikan hasil penelitian melalui jurnal ilmiah dan conference, dan mengikuti berbagai pelatihan atau seminar. Dukungan yang diberikan bersifat dukungan moril dan juga materil seperti bantuan pendanaan. 
UTama mengeluarkan biaya yang tidak sedikit dalam memberikan dukungan kepada dosen - dosen untuk mengembangkan keilmuannya, namun perlu dilakukannya pengkajian ulang apakah pendanaan tersebut sudah memadai untuk mengcoverkebutuhan para dosen yang melakukan studi lanjut, publikasi karya ilmiah ataupun pelatihan. Dalam melakukan studi lanjut, banyak biaya yang dikeluarkan di luar biaya pendidikan yang tidak menjadi tanggungan dalam pendanaan. Begitupun dalam melakukan publikasi karya ilmiah atau pelatihan dimana dana yang dikeluarkan oleh dosen untuk melakukan publikasi lebih besar dibandingkan dana yang diberikan oleh institusi. Hal ini tentunya akan menjadi penghambat yang bisa menimbulkan demotivasi dosen untuk mengembangkan keilmuannya.

Human capital yang baik tidak akan mendapatkan hasil yang optimal jika tidak didukung oleh structural capital. Human capital berperan penting dalam organisasi yaitu sebagai lifeblood dalam intellectual capital sebagai sumber inovasi dan pengembangan (Suhardjanto dan Wardhani, 2010). Berbagai fasilitas pendukung proses pembelajaran perlu dipelihara dengan baik dan harus mengikuti perkembangan teknologi terkini. Fasilitas pendukung pembelajaran ini seperti proyektor LCD, referensi terbaru, juga pengadaan wifi.

Pendanaan structural capital sudah dialokasikan dengan cukup baik. Structural capital lebih merujuk kepada organizational capital yang berarti bahwa kemampuan organisasi dalam memenuhi proses rutinitas organisasi dan strukturnya yang mendukung usaha anggota untuk menghasilkan kinerja intelektual secara optimal (Suhardjanto dan Wardhani, 2010). Namun, kebijakan mengenai alokasi pendanaan khususnya pendanaan pemeliharaan pada structure capital perlu dipertimbangkan kembali demi terwujudnya kegiatan pembelajaran yang lebih efektif. Hal ini disebabkan tersedianya fasilitas pendukung pembelajaran yang cukup lengkap, tetapi tidak selalu berfungsi dengan baik. Proyektor LCD sudah tersedia di setiap ruangan, namun pada prakteknya masih saja terjadi permasalahan seperti tidak berfungsinya proyektor tersebut. Hal ini tentunya memperlambat kegiatan pembelajaran karena dosen harus menghubungi bagian fasilitas untuk mengatasi permasalahan tersebut atau mencari ruangan lain untuk melanjutkan kegiatan pengajaran. Permasalahan lain yang sering muncul adalah sulitnya melakukan koneksi internet dikarenakan koneksi wifi yang kurang kuat. Hal ini juga tentunya menghambat kegiatan pembelajaran dikarenakan banyak contoh dari penjelasan materi atau referensi yang memerlukan koneksi internet untuk mengaksesnya. 
Aspek lain yang mendukung human capital dan structural capital adalah relational capital. Hubungan dengan berbagai pihak perlu dibina dan dijaga agar terbangunnya kepercayaan dari pihak eksternal. UTama mengadakan kegiatan Pengabdian Kepada Masyarakat (PKM) untuk membangun hubungan dengan masyarakat. UTama juga menjalin kerja sama penelitian, pengerjaan proyek -proyek dengan pihak eksternal. Selain itu, kerjasama dengan media pun dilakukan agar nama UTama semakin dikenal dan dipercaya oleh masyarakat.

Beberapa hubungan telah dibina dengan pihak eksternal, namun dampak dari kerja sama tersebut belum begitu terasa oleh civitas akademika. Oleh karena itu, UTama perlu lebih agresif dalam menjalin hubungan dengan berbagai lembaga eksternal dan masyarakat dalam kaitannya dengan pengembangan keilmuan agar bisa lebih meningkatkan kredibilitas institusi.

Pengungkapan human capital, structural capital, dan relational capital pada sebuah universitas dibutuhkan untuk membantu mengidentifikasi struktur, kekuatan dan kelemahan agar dapat menaikkan nilai universitas yang salah satunya tercermin pada akreditasi dari universitas tersebut.

\section{Metodologi}

Menurut Sugiono (2010:2) metode penelitian adalah cara ilmiah yang digunakan guna mendaparkan data dengan tujuan dan kegunaan tertentu. Penelitian ini bertujuan untuk mengetahui apakah terdapat pengaruh Intellectual capital terhadap akreditasi. Pendekatan yang digunakan adalah model exploratory research dengan metode penelitian asosiatif. Sangaji \& Sopiah (2010:30) menyatakan bahwa penelitian asosiatif (hubungan) merupakan penelitian yang bertujuan mengetahui hubungan antara dua variabel atau lebih. Tujuan Penelitian asosiatif adalah melihat apakah ada pengaruh dan seberapa besar pengaruh dari sebab akibat atau dari variabel independen dan dependen penelitian. Penelitian ini bertujuan untuk mengetahui pengaruh intellectual capital terhadap akreditasi. Berdasarkan tujuan tersebut, penelitian ini memiliki variabel bebas yaitu intellectual capital yang diukur dengan human capital (X1), structure capital (X2), dan relational capital (X3), serta variabel terikat yaitu Akreditasi (Y) pada Universitas Widyatama. Unit analisis dari penelitian ini adalah dosen dan pejabat struktural pada Universitas Widyatama. 


\section{Populasi dan Sampel}

Populasi dalam penelitian ini yaitu seluruh dosen dan pejabat struktural, dengan rincian sebagai berikut :

1. Pejabat sebanyak 112 orang terdiri dari 44 orang pejabat akademik dan 68 orang pejabat administratif

2. Dosen sebanyak 266 orang dosen tetap

Dari populasi yang ada sebanyak 388 responden dengan 122 pejabat struktural dan 266 dosen tetap dan seluruh populasi dijadikan sampel.

\section{Metode Analisis Data}

Penelitian ini menggunakan metode Structural Equation Modeling (SEM) untuk menguji model struktural dan hipotesis. Menurut Ghozali (2008) Structural Equation Modelling (SEM) adalah sebuah evolusi dari model persamaan berganda yang dikembangkan dari prinsip ekonometri dan digabungkan dengan prinsip pengaturan dari psikologi dan sosiologi, SEM telah muncul sebagai bagian integral dari penelitian manajerial akademik. Jumlah observasi (pengamatan) merupakan hal yang sangat penting untuk dapat menggunakan metode ini, maka penentuan jumlah sampel merupakan hal pokok dalam metode ini. Yoon dalam Chung-Hsing (2002) menyatakan bahwa dalam SEM terdapat rasio minimum yaitu 5 responden untuk setiap parameter dalam penelitian, atau 10 responden untuk setiap 1 parameter, atau 15 responden untuk setiap 1 parameter. Penelitian ini menggunakan sampel penelitian sebanyak 378 responden.

\section{Hasil dan Pembahasan}

Setelah dilakukan analisis faktor konfirmatori (CFA) terhadap masing-masing variabel, selanjutnya adalah analisis full model struktural untuk membentuk model struktural secara fit. Hasil pendugaan untuk analisis full model struktural ditampilkan seperti pada Gambar 1 berikut 


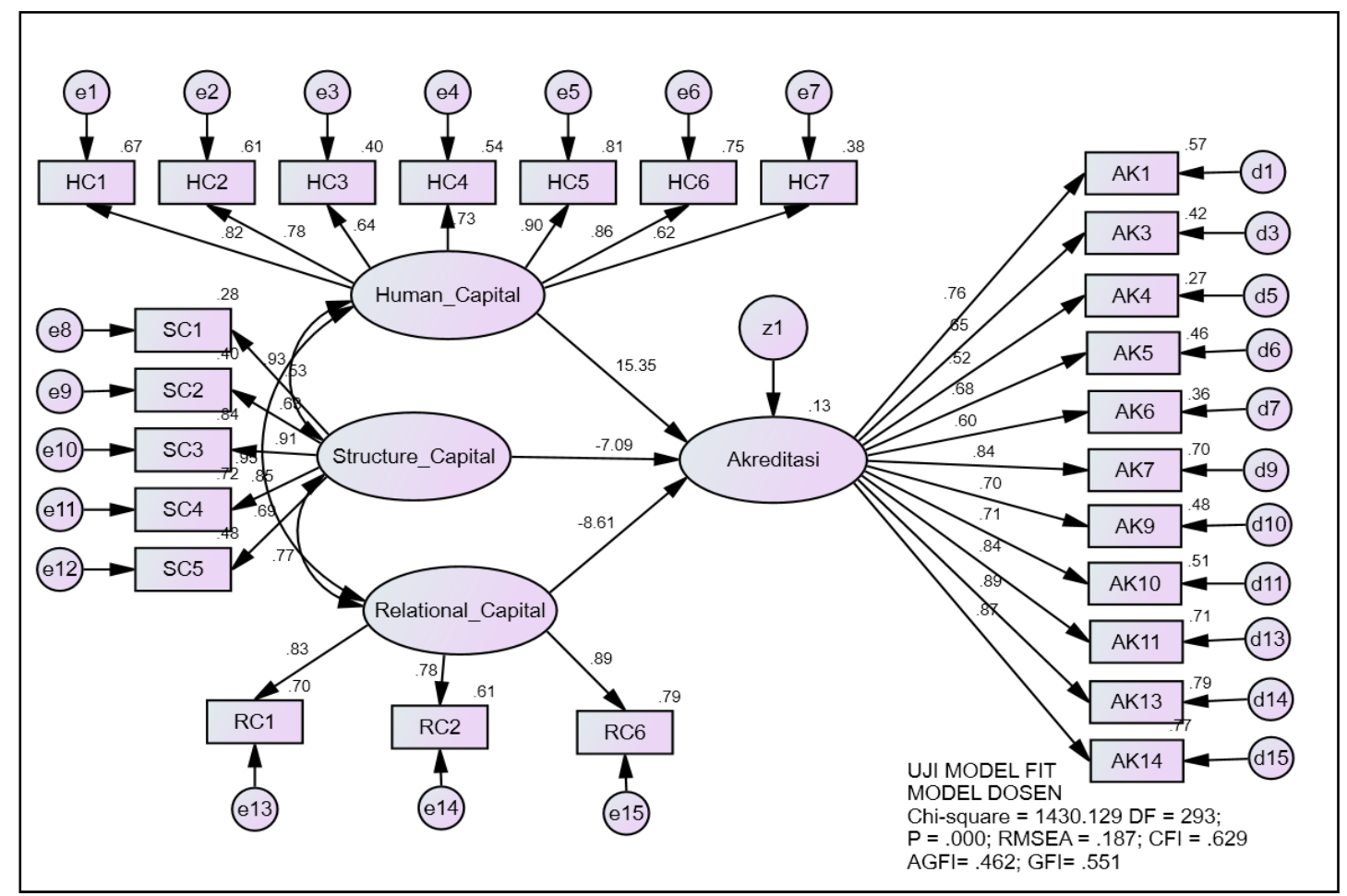

Gambar 1 Hasil Pendugaan Full Model.

Gambar 1 menunjukkan besaran nilai-nilai parameter pada hubungan antar variabel laten yang ada serta besaran nilai-nilai loading factor masing-masing indikator pembentuk variabel laten. Dilihat dari nilai-nilai parameter yang ada terlihat bahwa hubungan antara variabel eksogen dengan variabel endogen ada yang bersifat negatif dan ada juga yang bersifat positif. Gambar tersebut juga menunjukkan besarnya pengaruh faktor-faktor komunikasi pemasaran terpadu terhadap perilaku pemilih dan keputusan memilih.

Nilai Goodnes of Fit dari model struktural yang terbentuk terlihat seperti pada Tabel 2 berikut:

Tabel 2: Nilai GOF pada Full Model Struktural

\begin{tabular}{ccccc}
\hline No & Kriteria & Nilai Batas & Hasil & Kesimpulan \\
\hline 1 & Significance probability $X^{2-}$ chi square & $\geq 0,05$ & 0,00 & Tidak Fit \\
\hline 2 & RMSEA & $\leq 0,08$ & 0.18 & Tidak Fit \\
\hline 3 & GFI & $\geq 0,90$ & 0.55 & Tidak Fit \\
\hline 4 & AGFI & $\geq 0,90$ & 0,46 & Tidak Fit \\
\hline 5 & CFI & $\geq 0,90$ & 0,63 & Tidak Fit \\
\hline 6 & NNFI/TLI & $\geq 0,90$ & 0,58 & Tidak Fit \\
\hline 7 & NFI & $\geq 0,90$ & 0,62 & Tidak Fit \\
\hline 8 & RMR & $\leq 0,05$ & 0.06 & Tidak Fit \\
\hline
\end{tabular}

Tabel 2 terlihat bahwa hampir semua kriteria statistik goodness of fit (GOF) belum fit, khususnya RMSEA. Nilai chi-square yang kecil atau yang tidak signifikan 
sulit terpenuhi khusunya pada sampel besar (Hair et al., 2014), akan tetapi bukan berarti model tidak cocok, untuk itu disarankan untuk menggunakan kriteria kecocokan yang lainnya (Hair et al., 2014). Berdasarkan konsensus, kriteria RMSEA lebih banyak digunakan untuk melihat kecocokan suatu model. Berdasarkan hasil tersebut dapat dinyatakan bahwa model yang terbentuk belum fit, sehingga tidak dapat dijadikan sebagai model prediksi.

Tabel 3: Hasil Pengujian Analisis Full Model

\begin{tabular}{|c|c|c|c|c|c|c|c|}
\hline \multicolumn{3}{|c|}{ Hubungan } & Estimate & S.E. & C.R. & $\mathbf{P}$ & Keterangan \\
\hline Akreditasi & $<--$ & Human_Capital & 11.486 & 234.461 & .049 & .961 & $\begin{array}{c}\text { Tidak } \\
\text { Signifikan }\end{array}$ \\
\hline Akreditasi & $<---$ & Structure_Capital & -7.124 & 155.795 & -.046 & .964 & $\begin{array}{c}\text { Tidak } \\
\text { Signifikan }\end{array}$ \\
\hline Akreditasi & $<--$ & Relational_Capital & -6.925 & 143.357 & -.048 & .961 & $\begin{array}{c}\text { Tidak } \\
\text { Signifikan }\end{array}$ \\
\hline AK1 & $<--$ & Akreditasi & 1.000 & & & & Signifikan \\
\hline AK3 & $<--$ & Akreditasi & .724 & .106 & 6.865 & *** & Signifikan \\
\hline AK4 & $<--$ & Akreditasi & .666 & .122 & 5.450 & *** & Signifikan \\
\hline AK5 & $<--$ & Akreditasi & .696 & .095 & 7.352 & $\star * *$ & Signifikan \\
\hline AK6 & $<--$ & Akreditasi & .479 & .075 & 6.389 & *** & Signifikan \\
\hline AK7 & $<--$ & Akreditasi & 1.014 & .110 & 9.249 & *** & Signifikan \\
\hline AK9 & $<---$ & Akreditasi & .990 & .131 & 7.551 & *** & Signifikan \\
\hline AK10 & $<--$ & Akreditasi & .853 & .110 & 7.762 & *** & Signifikan \\
\hline AK11 & $<--$ & Akreditasi & .934 & .098 & 9.485 & *** & Signifikan \\
\hline AK13 & $<--$ & Akreditasi & 1.345 & .134 & 10.009 & *** & Signifikan \\
\hline $\mathrm{HC} 1$ & $<--$ & Human_Capital & 1.000 & & & & Signifikan \\
\hline $\mathrm{HC2}$ & $<--$ & Human_Capital & .719 & .074 & 9.676 & *** & Signifikan \\
\hline $\mathrm{HC} 3$ & $<--$ & Human_Capital & .542 & .074 & 7.324 & $* * *$ & Signifikan \\
\hline $\mathrm{HC} 4$ & $<--$ & Human_Capital & .746 & .085 & 8.734 & $\star \star \star *$ & Signifikan \\
\hline HC5 & $<--$ & Human_Capital & .664 & .056 & 11.939 & $\star \star \star *$ & Signifikan \\
\hline HC6 & $<--$ & Human_Capital & .701 & .062 & 11.223 & $* \star *$ & Signifikan \\
\hline SC2 & $<--$ & Structure_Capital & 1.000 & & & & Signifikan \\
\hline SC1 & $<--$ & Structure_Capital & .669 & .136 & 4.937 & *** & Signifikan \\
\hline SC3 & $<--$ & Structure_Capital & 1.428 & .191 & 7.461 & $\star \star \star *$ & Signifikan \\
\hline SC4 & $<--$ & Structure_Capital & 1.181 & .161 & 7.347 & $* * *$ & Signifikan \\
\hline SC5 & $<--$ & Structure_Capital & .898 & .144 & 6.247 & $* \star \star$ & Signifikan \\
\hline $\mathrm{RC} 1$ & $<--$ & Relational_Capital & 1.000 & & & & Signifikan \\
\hline $\mathrm{RC} 2$ & $<--$ & Relational_Capital & .706 & .074 & 9.589 & *** & Signifikan \\
\hline $\mathrm{HC} 7$ & $<--$ & Human_Capital & .743 & .105 & 7.068 & $\star \star \star *$ & Signifikan \\
\hline $\mathrm{RC6}$ & $<--$ & Relational_Capital & .717 & .064 & 11.278 & $* \star *$ & Signifikan \\
\hline AK14 & $<--$ & Akreditasi & 1.382 & .140 & 9.869 & $* * *$ & Signifikan \\
\hline
\end{tabular}

Berdasarkan Gambar 1 terlihat bahwa semua indikator pembentuk variabel laten sudah signifikan (nilai t lebih besar dari 1,96), namun hasil pengujian untuk hubungan antar variabel laten semua tidak signifikan.

Besarnya pengaruh variabel eksogen terhadap variabel endogen terlihat seperti pada Tabel 4. 
Tabel 4: Besaran Pengaruh antar Variabel

\begin{tabular}{ccccc}
\hline Variabel & Parameter & Uji-t & p-value & Keterangan \\
\hline Human_Capital $\left(\mathrm{H}_{1}\right)$ & 15,353 & 0.049 & 0.961 & Tolak Hipotesis \\
Structure_Capital $\left(\mathrm{H}_{2}\right)$ & $-7,094$ & -0.046 & 0.964 & Tolak Hipotesis \\
Relational_Capital $\left(\mathrm{H}_{3}\right)$ & $-8,607$ & -0.048 & 0.961 & Tolak Hipotesis \\
\hline
\end{tabular}

Tabel 4 menunjukkan bahwa faktor yang paling dominan berpengaruh terhadap akreditasi adalah human capital, yaitu sebesar $15,35 \%$, namun secara statistik tidak berpengaruh signifikan. Secara keseluruhan faktor intelectual capital tidak berpengaruh terhadap akreditasi, bahkan relational dan structural capital memiliki pengaruh yang negatif terhadap akreditasi, meskipun secara statistik tidak signifikan.

\section{Kesimpulan}

Indikator-indikator yang dirumuskan dalam model akhir variabel human capital sudah valid dan reliabel, sehingga model akhir pengukuran human capital sudah dapat dijadikan sebagai manifest bagi konstruk variabel human capital pada pembentukan full model. Indikator dari human capital yang paling dominan dalam menjelaskan variabel laten adalah indikator HC5.

Indikator-indikator yang dirumuskan dalam model akhir variabel Structure capital sudah valid dan reliabel, sehingga model akhir pengukuran Structure capital sudah dapat dijadikan sebagai manifest bagi konstruk variabel Structure capital pada pembentukan full model. Indikator dari Structure capital yang paling dominan dalam menjelaskan variabel laten adalah indikator SC3.

Indikator-indikator yang dirumuskan dalam model akhir variabel Relational capital sudah valid dan reliabel, sehingga model akhir pengukuran Relational capital sudah memenuhi kriteria model pengukuran yang baik (fit) dan dapat dijadikan sebagai manifest bagi konstruk variabel relation capital pada pembentukan full model. Indikator dari Relational capital yang paling dominan dalam menjelaskan variabel laten adalah indikator RC6.

Indikator-indikator yang dirumuskan dalam model awal pengukuran variabel Akreditasi belum valid dan reliabel, maka perlu dilakukan proses pembentukan model yang baru pada CFA Akreditasi yang memenuhi validitas dan reliabilitas.

Indikator-indikator yang dirumuskan dalam model akhir variabel Akreditasi sudah valid dan reliabel, sehingga model akhir pengukuran Akreditasi sudah memenuhi kriteria model pengukuran yang baik (fit) dan dapat dijadikan sebagai 
manifest bagi pembentukan full model. Indikator dari Akreditasi yang paling dominan dalam menjelaskan variabel laten adalah indikator AK13.

Faktor yang paling dominan berpengaruh terhadap akreditasi adalah human capital, yaitu sebesar 15,35\%, namun secara statistik tidak berpengaruh signifikan. Secara keseluruhan faktor intelectual capital tidak berpengaruh terhadap akreditasi, bahkan relational dan structural capital memiliki pengaruh yang negatif terhadap akreditasi, meskipun secara statistik tidak signifikan.

\section{Saran}

Terlihat bahwa hampir semua kriteria statistik goodness of fit (GOF) belum fit, khususnya RMSEA. Nilai chi-square yang kecil atau yang tidak signifikan sulit terpenuhi khusunya pada sampel besar (Hair et al., 2014), Berdasarkan konsensus, kriteria RMSEA lebih banyak digunakan untuk melihat kecocokan suatu model. Berdasarkan hasil tersebut dapat dinyatakan bahwa model yang terbentuk belum fit, sehingga tidak dapat dijadikan sebagai model prediksi.

\section{Daftar Referensi}

Chung-Hsing, Yeh 2002. A Problem-based Selection of Multi-Attribute Decision Making Methods. International Transactions in Operational Research. Blackwell Publishing.

Gibb, Y.K., \& Blili, S. 2012. Business Strategy and Governance of Intellectual Assets in Small \& Medium Enterprises, Procedia-Social and Behavioral Sciences 75 (2013) 420 - 433, available online at www.sciencedirect.com.

Ghozali, Iman. 2008. Aplikasi Analisis Multivariate dengan Program SPSS. Semarang: Badan Penerbit Universitas Diponegoro.

Hair, et al. 2014. Multivariate Data Analysis, New International Edition., New Jersey: Pearson.

Kostagiolas, P. 2012. Managing Intellectual Capital in Libraries, Beyond the Balance Sheet, Chandos Information Professional Series

Sangaji, Etta Mamang dan Sopiah. 2010. Metodologi Penelitian. ANDI. Yogyakarta

Sugiono. 2010. Metode Penelitian Pendidikan Pendekatan Kuantitatif, Kualitatif, dan $R \& D$. Bandung: Alfabeta.

Suhardjanto, Djoko dan Wardhani, Mari. 2010. Praktik Intellectual Capital Disclosure Perusahaan yang Terdaftar di Bursa Efek Indonesia. JAAI Volume 14 No 1 Juni 2010. $\mathrm{Pg} 71-85$

https://uharsputra.wordpress.com/pendidikan/pend-tinggi/perguruan-tinggi-dantantangannya/ 